\title{
Effectiveness of role-play in hazard prediction training for nursing students: A randomized controlled trial
}

\author{
Yasuyo Sato ${ }^{* 1,2}$, Sachiko Okamoto ${ }^{2}$, Kazunori Kayaba ${ }^{1}$, Hiroaki Nobuhara ${ }^{1}$, Keiko Soeda ${ }^{1}$ \\ ${ }^{1}$ Department of Health and Social Services, Graduate School of Saitama Prefectural University, Saitama, Japan \\ ${ }^{2}$ Department of Health Science, Japan University of Health Sciences, Saitama, Japan
}

Received: August 8, 2017

DOI: $10.5430 /$ jnep.v8n2p1
Accepted: September 12, $2017 \quad$ Online Published: September 25, 2017

URL: https://doi.org/10.5430/jnep.v8n2p1

\begin{abstract}
Objective: Patient safety education in nursing education is a matter of worldwide concern. Various simulation training has been introduced into patient safety education. It is difficult for nursing students to fully understand the situation of scenarios in simulation training. Having attempted to solve the problem, educators have used the illustrations, videos and manikins. Role-play is widely used in simulation training in nursing education. As to patient safety education, few randomized controlled trials (RCTs) have reported the effectiveness of role-play compared with traditional situational presentation methods such as illustrations and videos. Therefore, we performed an RCT to examine the effectiveness of role-play compared with illustrations using hazard prediction training (Kiken-Yochi-Training; KYT) which is one of simulation training widely used in Japan.

Methods: The participants were 94 second-year nursing students. All students were randomly allocated to a role-play group (R-group) or an illustrations group (I-group). Participants were asked to complete the risk sensitivity scale for nursing students before and after KYT. After KYT, all participants were asked to undergo a hazard prediction test. Linear mixed models were used to examine differences in the scale scores within and between intervention groups.

Results: Participants in the R-group had a significantly higher number of hazard prediction points than those in the I-group (R-group: $2.50 \pm 1.07$, I-group: $1.77 \pm 0.95, p=.001$ ). Scores were significantly increased on the risk sensitivity scale for nursing students in both groups, while no significant differences were seen in score increments between the groups.

Conclusions: The results of our randomized study showed that effectiveness of role-play in hazard prediction training in university-based nursing education. Our study also suggested KYT increased risk sensitivity among nursing students, and that this effect was not affected by the situation presentation method, role-play or illustration.
\end{abstract}

Key Words: Hazard prediction training, Patient safety, Role-play, Nursing education, Risk sensitivity

\section{INTRODUCTION}

Patient safety education in nursing education is a matter of worldwide concern. ${ }^{[1,2]}$ In 2009 , an ordinance issued by the Ministry of Health, Labour and Welfare in Japan stressed the need for patient safety education in nursing education curricula. ${ }^{[3]}$ The Quality and Safety Education for Nurses initiative (QSEN) states that, to provide patient safety, nurses need to minimize risk of harm to patients through individual performance. $^{[4]}$

To promote the individual performance, various simulation training has been introduced into patient safety education. ${ }^{[5-8]}$ In the simulation training, students can experience the variety of clinical scenarios. Nursing students have insufficient knowledge and clinical experience; therefore, it is

*Correspondence: Yasuyo Sato; Email: 1791004x@spu.ac.jp; Address: 820 San-Nomiya, Koshigaya-shi, Saitama 343-8540, Japan. 
difficult for students to fully understand the situation of scenarios. ${ }^{[9]}$ Having attempted to solve the problem, educators have used the illustrations, ${ }^{[10]}$ videos ${ }^{[11]}$ and manikins. ${ }^{[5]}$

Role-play is a way of deliberately constructing an approximation of the aspects of a real experience, ${ }^{[12]}$ and affords situational learning without compromising patient safety. ${ }^{[13]}$ Role-play is widely used in simulation training in nursing education of medication administration competency, ${ }^{[14]} \mathrm{com}$ munication skill ${ }^{[15]}$ and interprofessional work. ${ }^{[16]}$ As to patient safety education, to the best of our knowledge, few randomized controlled trials (RCTs) have reported the effectiveness of role-play compared with traditional situational presentation methods such as illustrations and videos.

Therefore, we performed an RCT to examine the effectiveness of role-play compared with illustrations using hazard prediction training (Kiken-Yochi-Training; KYT) which is one of simulation training widely used in Japan.

\section{MethodS}

\subsection{Study design}

This was a two-arm randomized controlled study with nursing students as participants.

\subsection{Participants}

Of 102 second-year nursing students at a Japanese university, 94 (92.2\%) agreed to participate. All of the participants had completed their first year of clinical practice. We excluded students who disagreed or were absence from the trial practice.

\subsection{Intervention}

The KYT Basic 4-Round method ${ }^{[17]}$ was implemented using role-play and illustrations for situational presentations. In Japan, KYT has been widely adopted in nursing education. ${ }^{[18]} \mathrm{KYT}$ is a type of simulation training that originated as an industrial safety training program in Japan. ${ }^{[17]}$ The purpose of KYT is to predict risks in job situation in illustrations. A systematic review reported that KYT reduced the occupational accident rate. ${ }^{[19]}$ Thereafter, KYT was introduced into safety education programs in continuing medical education, ${ }^{[20,21]}$ leading to a significant reduction in accidents. ${ }^{[22,23]}$

\subsection{Outcomes}

We hypothesized that KYT using role-play would increase sensitivity to hazardous situations in the medical care setting and consequently enhance students' hazard prediction ability. Therefore, we selected two outcome measures: a hazard prediction test to evaluate increases in hazard prediction ability and the risk sensitivity scale for nursing students to measure the level of risk sensitivity. ${ }^{[24]}$

The hazard prediction test is an original measurement tool developed by the authors. This test presents a nursing situation to the test subjects using a video, and the subjects' responses are indicated as a number of hazard points that they point out. The video was developed to help nurses prevent medical accidents, and it has been utilized for risk management in clinical settings and continuing nursing education in Japan. ${ }^{[25]}$ Before implementing the test, researchers established the evaluation criteria for the hazard points. These criteria exclude cases assumed not to be in the given setting, those not regarded as hazardous, those not written in a designated way, and those with duplicate descriptions. The evaluators were trained based on these criteria and were masked to the allocation of the participants.

The risk sensitivity scale for nursing students consists of 25 items and was developed for first to fourth year nursing students in Japan. ${ }^{[24]}$ Using a Likert scoring system (1-2-3-45-6), items were summed to give a total risk sensitivity score. This scale consists of six subscales: "ability to execute safety acts", "ability to use risk experiences", "ability to acquire risk information", "risk avoidance preparedness", "risk response preparedness", and "risk detecting and monitoring ability". Cronbach's $\alpha$ coefficient for the total score was 0.93 . The subscales had similar $\alpha$ coefficients (0.85-0.91). Acceptable levels of content validity, correlations with external reference scales and construct validity were reported. Construct validity was evaluated using exploratory and confirmatory factor analysis. A high goodness of fit value was attained for a model comprised of the six subscales.

\subsection{Sample size determination}

Sample size calculation was estimated using information from a previous article that described the measurement characteristics of the risk sensitivity scale for nursing students. ${ }^{\text {[24] }}$ The mean overall risk sensitivity scale score was 3.85 (standard deviation [SD], 0.64), with the mean score of each subscale ranging from 3.26-4.05 (SD range, 0.75-1.11). When the SD was assumed to be 1.00 by six evaluation points, the sample size calculation indicated that 44 participants were required per arm to detect a difference of 0.6 with a $5 \%$ significance level.

\subsection{Randomization}

The participants were randomly allocated to either a role-play group (R-group) or an illustration group (I-group), and to subgroups, each of which consisted of 5 or 6 participants, ${ }^{[26]}$ using a computer-generated allocation schedule. KYT was conducted in an open-label manner, and the evaluators of the 
hazard prediction test were masked to the allocation of the participants.

\subsection{Procedures}

The details of the intervention procedures are shown in Figure 1. A total of 94 nursing students participated in the study and were asked to complete questionnaires regarding their background characteristics and risk sensitivity. After introduction to the case scenario, instructors described a scene in which the patient walks from his bed in the patient room for the first time after the operation.

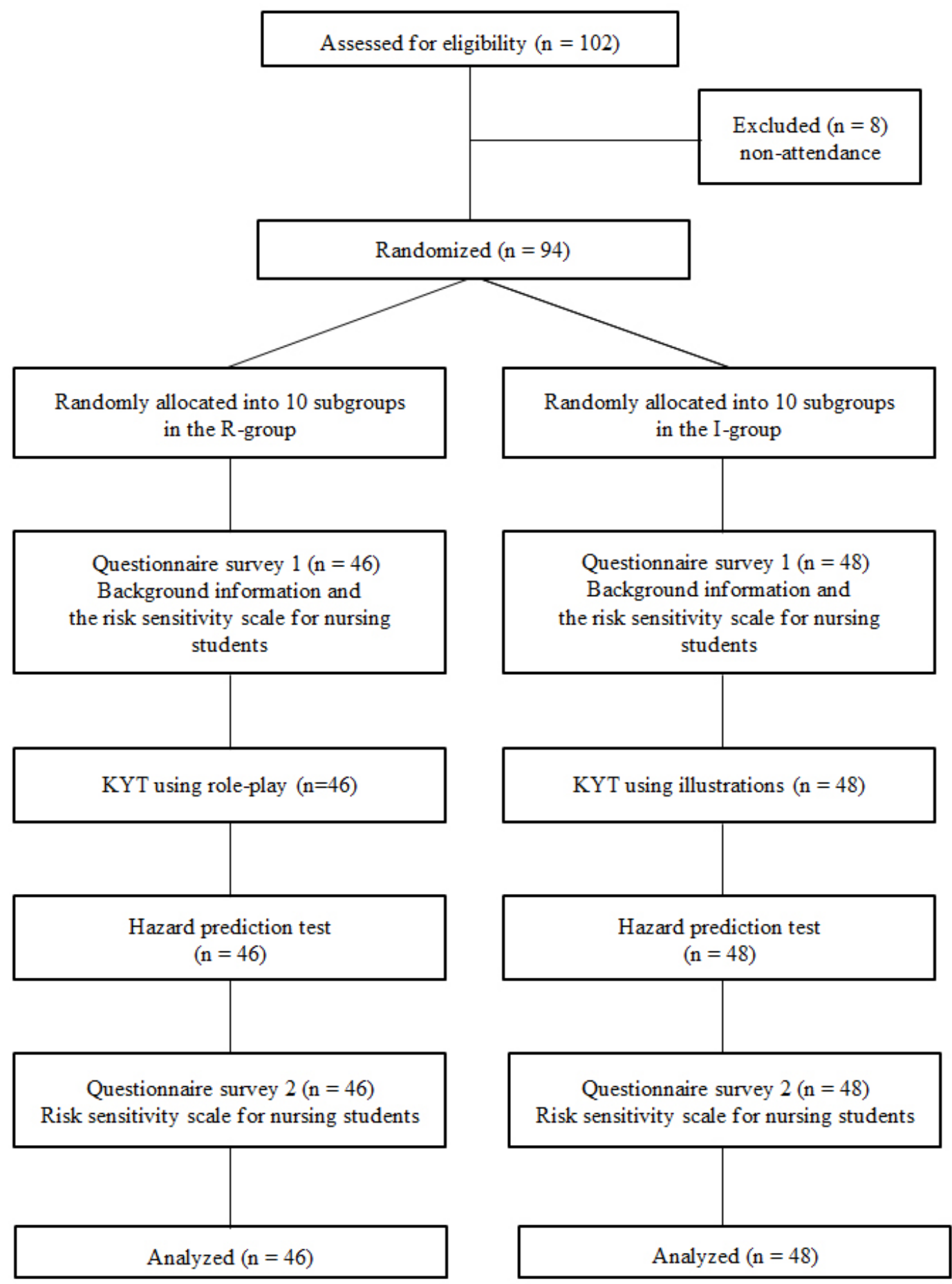

Figure 1. Flow diagram of the present randomized controlled Intervention was implemented using either role-play or illustrations in the KYT Basic 4-Round method 
In the first round of KYT, participants were urged to discuss situational hazards with other members of their own subgroup. In the I-group, instructors distributed an A4-size illustration sheet to each subgroup that showed a scene in which the postoperative patient rose from his bed to walk for the first time. In the scene, a nurse was standing near the patient. Researchers designed the illustration sheet with reference to previous illustrations. ${ }^{[27]}$ In the R-group, with assistance from the instructors, participants performed the role-play exercise as the postoperative patient and the nurse. Thereafter, all participants in both groups listed all identifiable hazard points. In the second round, the participants decided which of the hazard points issued in the first round was considered the most serious. In the third round, the participants established countermeasures against the hazard points extracted in the second round. In the fourth round, the participants narrowed their selections down to one countermeasure they considered to have the highest priority.

After finishing KYT, all participants were asked to take the hazard prediction test. The participants were instructed to watch a video recording of a case twice and then completed a form addressing what kinds of situational hazards they could identify. They then listed all of the hazard points that they considered as risk factors. The video showed a scene in which a male patient with a chest drainage apparatus was lying on a bed while nurses attempted to change his posture. The number of hazard points identified by the participants was counted as the score. Finally, after the test, they completed the questionnaire on risk sensitivity again. It took approximately $90 \mathrm{~min}$ for students to complete KYT, the questionnaires, and the hazard prediction test.

\subsection{Ethical considerations}

Participation in KYT was a requirement for the nursing course. Students who did not wish to participate in the study were allowed to opt out. This study was reviewed and approved by the research ethics committee of the authors' institutions and registered in a publicly accessible database. All of the participants provided written informed consent to participate, and were informed that refusing to participate would not influence their course grades. For educational purposes, after this trial, the students who had been in the R-group participated in KYT using illustrations, while those who had been in the I-group participated in KYT using role-play.

\subsection{Data analysis}

The chi-square test was used to examine differences in background characteristics between the two groups. Descriptive statistics were reported as means and standard deviations. A linear mixed model univariate procedure was used to examine differences in hazard prediction test scores. A paired t-test and a linear mixed model repeated measure procedure were used to compare risk sensitivity scale scores within and between intervention groups, respectively. In the models, subgroups were nested within intervention groups. Data were analyzed using SPSS for Windows (version 24.0, IBM Corp., Armonk, NY, USA). $p$ values $<.05$ were considered statistically significant.

\section{RESULTS}

\subsection{Background characteristic of the participants}

The participants' background characteristics are shown in Table 1. No statistically significant differences were found for any variables between the R- and I-groups.

Table 1. Background characteristics of the trial participants

\begin{tabular}{|c|c|c|c|c|}
\hline \multirow{2}{*}{ Characteristics } & \multicolumn{2}{|c|}{ Role-play group } & \multicolumn{2}{|c|}{ Illustration group } \\
\hline & \multicolumn{2}{|c|}{$(n=46)$} & \multicolumn{2}{|c|}{$(n=48)$} \\
\hline \multicolumn{5}{|l|}{ Sex } \\
\hline Female & 38 & $(82.6 \%)$ & 42 & $(87.5 \%)$ \\
\hline Male & 8 & $(17.4 \%)$ & 6 & $(12.5 \%)$ \\
\hline \multicolumn{5}{|l|}{ Age (years) } \\
\hline 19 & 31 & $(67.4 \%)$ & 29 & $(60.4 \%)$ \\
\hline 20 & 9 & $(19.6 \%)$ & 17 & $(35.4 \%)$ \\
\hline 21 & 1 & $(2.2 \%)$ & 2 & $(4.2 \%)$ \\
\hline 22 & 0 & $(0.0 \%)$ & 0 & $(0.0 \%)$ \\
\hline$\geq 23$ & 5 & $(10.9 \%)$ & 0 & $(0.0 \%)$ \\
\hline \multicolumn{5}{|c|}{ Working experience in medical or nursing facilities } \\
\hline Yes & 2 & $(4.3 \%)$ & 1 & $(2.1 \%)$ \\
\hline No & 44 & $(95.7 \%)$ & 47 & $(97.9 \%)$ \\
\hline
\end{tabular}

\subsection{Hazard prediction test}

No hazard points identified by the participants were excluded according to the evaluation criteria. The participants in the R-group identified a significantly higher number of hazard prediction points than those in the I-group (R-group: $2.50 \pm$ 1.07, I-group: $1.77 \pm 0.95 ; p=.001$ ).

\subsection{Risk sensitivity scale scores}

The mean risk scores of sensitivity scale for nursing students in both groups before and after KYT are shown in Table 2. The post-KYT total and subscale scores were significantly higher than the pre-KYT scores in both groups, except for the "ability to execute safety acts" subscale in the R-group. On the other hand, no significant differences were seen between the two groups in terms of changes in scores after the intervention. 
Table 2. Results of the risk sensitivity scale for nursing students

\begin{tabular}{|c|c|c|c|c|c|c|c|c|c|c|c|c|c|}
\hline & \multicolumn{6}{|c|}{ Role-play group $(n=46)$} & \multicolumn{6}{|c|}{ Illustration group $(n=48)$} & \multirow{3}{*}{$\begin{array}{l}\text { Between } \\
\text { group } \\
\text { difference } \\
p \text {-value }{ }^{\S}\end{array}$} \\
\hline & \multirow{2}{*}{$\begin{array}{l}\text { Pre-KYT } \\
\text { Mean } \pm \\
\text { SD }\end{array}$} & \multirow{2}{*}{$\begin{array}{l}\text { Post-KYT } \\
\text { Mean } \pm \\
\text { SD }\end{array}$} & \multirow[b]{2}{*}{$\mathbf{M D}^{\dagger}$} & \multicolumn{2}{|l|}{$95 \% \mathrm{CI}^{\ddagger}$} & \multirow[b]{2}{*}{$p$} & \multirow{2}{*}{$\begin{array}{l}\text { Pre-KYT } \\
\text { Mean } \pm \\
\text { SD }\end{array}$} & \multirow{2}{*}{$\begin{array}{l}\text { Post-KYT } \\
\text { Mean } \pm \\
\text { SD }\end{array}$} & \multirow[b]{2}{*}{$\mathbf{M D}^{\dagger}$} & \multicolumn{2}{|c|}{$95 \% \mathrm{CI}^{\ddagger}$} & \multirow[b]{2}{*}{$p$} & \\
\hline & & & & Lower & Upper & & & & & Lower & Upper & & \\
\hline $\begin{array}{l}\text { Total score on the } \\
\text { risk sensitivity scale } \\
\text { for nursing students }\end{array}$ & $\begin{array}{l}108.89 \pm \\
11.45\end{array}$ & $\begin{array}{l}121.63 \pm \\
15.88\end{array}$ & 12.74 & 9.83 & 15.65 & .000 & $\begin{array}{l}105.46 \pm \\
14.59\end{array}$ & $\begin{array}{l}118.19 \pm \\
19.85\end{array}$ & 12.73 & 7.72 & 17.73 & .000 & .997 \\
\hline \multicolumn{14}{|l|}{ Subscales } \\
\hline $\begin{array}{l}\text { Ability to execute } \\
\text { safety acts }\end{array}$ & $\begin{array}{l}36.04 \pm \\
3.11\end{array}$ & $\begin{array}{l}36.41 \pm \\
4.11\end{array}$ & 0.37 & -0.51 & 1.25 & .403 & $\begin{array}{l}36.00 \pm \\
3.36\end{array}$ & $\begin{array}{l}37.33 \pm \\
4.11\end{array}$ & 1.33 & 0.48 & 2.19 & .003 & .117 \\
\hline $\begin{array}{l}\text { Ability to use risk } \\
\text { experiences }\end{array}$ & $\begin{array}{l}17.63 \pm \\
2.98\end{array}$ & $\begin{array}{l}19.74 \pm \\
2.70\end{array}$ & 2.11 & 1.44 & 2.78 & .000 & $\begin{array}{l}16.56 \pm \\
4.24\end{array}$ & $\begin{array}{l}18.33 \pm \\
4.33\end{array}$ & 1.77 & 0.52 & 3.02 & .007 & .637 \\
\hline $\begin{array}{l}\text { Ability to aquire risk } \\
\text { information }\end{array}$ & $\begin{array}{l}16.02 \pm \\
3.71\end{array}$ & $\begin{array}{l}18.41 \pm \\
4.15\end{array}$ & 2.39 & 1.37 & 3.42 & .000 & $\begin{array}{l}15.69 \pm \\
4.38\end{array}$ & $\begin{array}{l}17.88 \pm \\
4.41\end{array}$ & 2.19 & 0.96 & 3.41 & .001 & .799 \\
\hline $\begin{array}{l}\text { Risk avoidance } \\
\text { preparedness }\end{array}$ & $\begin{array}{l}14.04 \pm \\
3.48\end{array}$ & $\begin{array}{l}17.67 \pm \\
4.01\end{array}$ & 3.63 & 2.67 & 4.59 & .000 & $\begin{array}{l}13.27 \pm \\
3.78\end{array}$ & $\begin{array}{l}16.52 \pm \\
4.59\end{array}$ & 3.25 & 1.98 & 4.52 & .000 & .634 \\
\hline $\begin{array}{l}\text { Risk response } \\
\text { preparedness }\end{array}$ & $\begin{array}{l}12.07 \pm \\
2.00\end{array}$ & $\begin{array}{l}14.39 \pm \\
2.40\end{array}$ & 2.33 & 1.70 & 2.95 & .000 & $\begin{array}{l}11.69 \pm \\
2.93\end{array}$ & $\begin{array}{l}13.73 \pm \\
3.15\end{array}$ & 2.04 & 1.17 & 2.91 & .000 & .597 \\
\hline $\begin{array}{l}\text { Risk detecting and } \\
\text { monitoring ability }\end{array}$ & $\begin{array}{l}13.09 \pm \\
2.01\end{array}$ & $\begin{array}{l}15.00 \pm \\
1.98\end{array}$ & 1.91 & 1.24 & 2.58 & .000 & $\begin{array}{l}12.25 \pm \\
2.46\end{array}$ & $\begin{array}{l}14.40 \pm \\
2.83\end{array}$ & 2.15 & 1.32 & 2.97 & .000 & .662 \\
\hline
\end{tabular}

\section{Discussion}

We performed a randomized controlled trial to compare the use of role-play and illustrations in KYT in patient safety education for second-year nursing students. The hazard prediction test scores were significantly higher in the R-group than in the I-group. Significant increases in risk sensitivity scale scores were observed for nursing students in both groups; however, no significant differences were found between groups in score increments.

\subsection{The R-group had a higher number of predicted haz- ard points than the I-group}

The participants in the R-group had significantly higher scores on the hazard prediction test than those in the I-group. The idea underlying the concept of role-play is asking someone to imagine that they are someone else in a particular situation. ${ }^{[28]}$ Role-play promotes new ideas, strategies, and values to improve performance, ${ }^{[29]}$ and can potentially provide improved awareness of subjects-in-action. ${ }^{[12]}$ A previous study reported that students gained personal insight into the behavior of patients and nurses through the experience of role-play. ${ }^{[30]}$ In this study, role-play enabled a better understanding of risk identification than illustrations.

\subsection{KYT increased the risk sensitivity scale scores for nursing students}

Some previous studies have reported that KYT improves risk sensitivity among nursing students. ${ }^{[31,32]}$ Our findings that KYT increased risk sensitivity scale scores for nursing students were consistent with those results. The risk sensitivity scale defines risk sensitivity as the ability to predict risks and show safety awareness. ${ }^{[24]}$ In KYT, particPublished by Sciedu Press ipants hold discussions with other members of their own subgroup to identify situational hazards and consider appropriate countermeasures. This process likely promotes the acquisition of more comprehensive knowledge regarding patient safety and improved attitudes for dealing with risks expected to arise in clinical practice. Regarding the "ability to execute safety acts" subscale, no significant differences were found in scores from before and after KYT in the Rgroup. This subscale measures the intention to implement and continue safety actions for risk avoidance. In a previous study, Miyazaki et al. found that students' risk sensitivity was lower in post-clinical than in pre-clinical practice. ${ }^{[32]}$ Students were aware of their limited ability to execute safety acts based on their experience in clinical practice, so they considered their ability insufficient for patient safety.

\subsection{Increments in risk sensitivity scale scores for nurs- ing students were not statistically significantly differ- ent between the two groups}

We hypothesized that role-play would facilitate more accurate situational understanding among students, thereby improving their ability to identify risks. However, our results seem to be inconsistent with this hypothesis. Although our study design cannot directly explain this inconsistency, two possible causes can be assumed. The first is that role-play did not provide a significant additive effect over illustrations. The other is that the risk sensitivity scale used in the present study was unable to detect this additive effect. Further research is needed to examine the mechanisms underlying incremental changes in risk sensitivity in KYT. 


\subsection{Strength of the study}

The primary strength of the present study was that it was a randomized controlled trial with a high response rate (92\%) and no dropouts. Therefore, the findings could provide strong evidence for the effectiveness of role-play in KYT.

\subsection{Limitations}

The present study did have some limitations. First, it was carried out in a single university, so careful consideration is necessary when generalizing the results. Second, the hazard prediction test is an original measurement tool developed by the authors. Evaluator subjectivity might have affected the scores and could have caused some measurement bias, even though the evaluation criteria were established and the evaluators were trained before implementation of KYT. Reliability of test has not yet been reported. Further studies are needed to evaluate this test. Third, although the reliability and validity of the risk sensitivity scale for nursing students has been confirmed, ${ }^{[24]}$ previous studies ${ }^{[33-36]}$ have suggested other constructs of risk prediction. If other constructs are used to evaluate risk prediction ability, the findings could differ from those in the present study.

\section{Conclusion}

The results of this randomized study suggest the effectiveness of role-play in hazard prediction training in university-based nursing education. The results also suggest that KYT can improve risk sensitivity among nursing students, and that this effect is not affected by the situation presentation method, role-play or illustration. However, careful consideration is necessary when generalizing our results to other educational settings. Further study is needed to clarify the mechanisms underlying the effectiveness of role-play in KYT.

\section{ACKNOWLEDGEMENTS}

We are grateful to Professor Midori Shimazaki for her English writing support.

\section{CONFLiCTS OF InTEREST Disclosure}

The authors declare that there is no conflict of interest statement.

\section{REFERENCES}

[1] World Health Organization. World Alliance for Patient Safety 2004 [cited 2017 June 21]. Available from: http://www . who.int/pa tientsafety/worldalliance/en/

[2] Kohn LT, Corrigan JM, Donaldson MS. To Err Is Human: Building a Safer Health System. Washington, DC, USA: National Academies Press; 1999.

[3] Ministry of Health Labour and Welfare. Revised the Act on Public Health Nurses, Midwives and Nurses 2009 [cited 2017 June 21] Available from: http://www.mhlw.go.jp/stf/shingi/2r9852 $000001 \mathrm{vb6s}-a t t / 2 r 9852000001 \mathrm{vbj5}$.pdf [in Japanese]

[4] Quality and Safety Education for Nurses, (QSEN). QSEN Competencies 2011 [cited 2017 August 28]. Available from: http://qsen.org/competencies/pre-licensure-ksas/.

[5] Ziv A, Small SD, Wolpe PR. Patient safety and simulation-based medical education. Medical Teacher. 2000; 22(5): 489-95. PMid: PMid:21271963 https://doi.org/10.1080/01421590050110 777

[6] Berndt J. Patient safety and simulation in prelicensure nursing education: An integrative review. Teaching \& Learning in Nursing. 2014; 9(1): 16-22. PMID: 104126007. https://doi.org/10.1016/j. teln.2013.09.001

[7] Liaw SY, Zhou WT, Lau TC, et al. An interprofessional communication training using simulation to enhance safe care for a deteriorating patient. Nurse Education Today. 2014; 34(2): 259-64. PMid:23518067 https://doi.org/10.1016/j.nedt.2013.02 .019

[8] Reime MH, Johnsgaard T, Kvam FI, et al. Simulated settings; powerful arenas for learning patient safety practices and facilitating transference to clinical practice. A mixed method study. Nurse Education in Practice. 2016; 21: 75-82. PMid:27769018 https: //doi.org/10.1016/j.nepr.2016.10.003
[9] Benner P, Tanner C, Chesla C. Expertise in Nursing Practice, Second Edition Caring, Clinical Judgment, and Ethics. New York, USA: Springer Publisher Company; 2009.

[10] Page GG, Saunders P. Written simulation in nursing. Journal of Nursing Education. 1978; 17(4): 28-32. PMid:25868

[11] Gotwals BA, Scholtz S. Video-Enhanced Simulation in Pediatric End-of-Life Care. Nursing Education Perspectives (Wolters Kluwer Health). 2016; 37(6): 360-2.

[12] Yardley-Matwiejczuk KM. Role play: theory and practice. London, UK: SAGE Publications; 1997.

[13] Braude P, Reedy G, Dasgupta D, et al. Evaluation of a simulation training programme for geriatric medicine. Age and Ageing. 2015; 44(4): 677-82. PMid:25953500 https://doi.org/10.1093/ag eing/afv049

[14] Hayes C, Power T, Davidson PM, et al. Nurse interrupted: Development of a realistic medication administration simulation for undergraduate nurses. Nurse Education Today. 2015; 35(9): 981-6. PMid:26216062 https://doi.org/10.1016/j.nedt.2015.07 .002

[15] Yu M, Kang KJ. Effectiveness of a role-play simulation program involving the sbar technique: A quasi-experimental study. Nurse Education Today. 2017; 53: 41-7. PMid:28433731 https://doi. org $/ 10.1016 / j$.nedt. 2017.04 .002

[16] Banerjee A, Slagle JM, Mercaldo ND, et al. A simulation-based curriculum to introduce key teamwork principles to entering medical students. BMC Medical Education. 2016; 16(1): 295.

[17] Japan International Center for Occupational Safety and Health. Concept of "Zero-accident Total Participation Campaign" 1999 [cited 2016 Oct. 27]. Available from: http://www.jniosh.go.jp/icp ro/jicosh-old/english/zero-sai/eng/ 
[18] Fuse J. Features of KYT approach to basic nursing education. The Japanese Journal of Nursing Science. 2011; 36(10): 868-77. [in Japanese]

[19] Noor Afifah Y, Irniza R, Emilia ZA, et al. Kiken Yochi Training (KYT) in reducing acidents at workplaces: a systematic review. International Journal of Public Health and Clinical Sciences. 2016; 3(3): 123-32.

[20] Hashida M, Kamezaki R, Goto M, et al. Quantification of hazard prediction ability at hazard prediction training (Kiken-Yochi Training: KYT) by free-response receiver-operating characteristic (FROC) analysis. Radiological Physics and Technology. 2017; 10(1): 106-12. PMid:27787667 https ://doi .org/10.1007/s12194-016-037 4-1

[21] Murai Y, Sato M, Yamaguchi H, et al. Introducing hazard prediction training 'KYT' to undergraduate pharmacy education on patient safety. Yakugaku Zasshi: Journal of The Pharmaceutical Society of Japan. 2009; 129(11): 1367-73. PMid:19881209 https: //doi.org/10.1248/yakushi.129.1367

[22] Ishiguchi M, Abe M. Improved safety awareness among staff against falling: introducing hazard prediction training. Journal of the Japanese Psychiatric Nurses Association Conference. 2012; 55(1): 274-5. [in Japanese]

[23] Aizawa K, Kugenuma T, Yamamoto Y, et al. The effect of introducing KYT aiming at improving the risk sensitivity of nurses: towards incident reduction. The Japanese Nursing Association Proceedings of Pediatric Nursing. 2010; 40: 165-7. [in Japanese]

[24] Minami T, Tamura A, Ichihara T. Development and reliability and validity testing of a risk sensitivity scale for nursing students. Japan Academy of Nursing Education. 2015; 24(3): 13-25. [in Japanese]

[25] Sugiyama R. Prevent medical accidents with KYT. Osaka, Japan: MEDICUS SHUPPAN; 2014. [in Japanese]

[26] Arita M, Matsukawa M, Ootake C, et al. A study on effective group organization in KYT. The Japanese Nursing Association Proceedings of Nursing Management. 2014; 44: 157-60. [in Japanese]

[27] Sugiyama R. Hazard Prediction Training textbook for nurses. Osaka, Japan: MEDICUS SHUPPAN; 2010. [in Japanese]
[28] Van Ments M. The effective use of role play. London, UK: Kogan Page Ltd; 1999.

[29] Rylatt A, Lohan K. Creating training miracles. Sydney, Australia: Pfeiffer; 1995.

[30] Fossen P, Stoeckel PR. Nursing Students' Perceptions of a Hearing Voices Simulation and Role-Play: Preparation for Mental Health Clinical Practice. Journal of Nursing Education. 2016; 55(4): 203-8 PMid:27023889 https : //doi .org/10.3928/01484834-20160 316-04

[31] Maruyama A, Shiga T, Harada C, et al. Learning the risk sensitivity of students by medical safety education introducing KYT. The Japanese Nursing Association Proceedings of Nursing Education. 2008; 39: 184-6. [in Japanese]

[32] Miyazaki I, Harada C, Shiga T, et al. Consideration on medical safety education programs incorporating KYT in nursing educationdifferences in learning related to the learning phase-. The Japanese Nursing Association Proceedings of Nursing Education. 2012; 42: 162-4. [in Japanese]

[33] Honma K, Enomoto T. Relationship between risk sensitivity and nurse characteristics/error type. The Japanese Nursing Association Proceedings of Nursing Management. 2015; 45: 288-91. [in Japanese]

[34] Michihiro M. Validity and reliability of a scale to determine the risk sensitivity of nurses. Bulletin of Hyogo University. 2011; 16: 211-8. [in Japanese]

[35] Tella S, Smith NJ, Partanen P, et al. Learning Patient Safety in Academic Settings: A Comparative Study of Finnish and British Nursing Students' Perceptions. Worldviews On Evidence-Based Nursing. 2015; 12(3): 154-64. PMid:25872460 https ://doi.org/10.111 $1 /$ wvn. 12088

[36] Härkänen M, Voutilainen A, Turunen E, et al. Systematic review and meta-analysis of educational interventions designed to improve medication administration skills and safety of registered nurses. Nurse Education Today. 2016; 41: 36-43. PMid:27138480 https: //doi.org/10.1016/j.nedt.2016.03.017 